\title{
Exploring the Antecedents and Consequences of Mal- Marketing in the Pharmaceutical Industry: A Case Study of Pakistan
}

\author{
Arshad Khushi Muhammad', Aasir Ali, ${ }^{2, *}$ Rab Nawaz Lodhi', Ume Kalsoom ${ }^{4}$ \\ ${ }^{1}$ Department of Business \& Management, University of Engineering and Technology, Lahore, Pakistan. \\ ${ }^{2}$ Noon Business School, University of Sargodha, Sargodha, Pakistan. \\ ${ }^{3}$ UCP Business School, University of Central Punjab, Lahore, Pakistan. \\ ${ }^{4}$ School of Social Science and Humanities, University of Management and Technology, Lahore, Pakistan.
}

Authors' Contributions

1 conceived, designed, writing, data collection and analysis

2 editing, proofreading, approval and

correspondence

3 editing and guidance

4 data analysis, editing and writing

\section{Article info.}

Received: January 03, 2020

Accepted: July 07, 2020

Funding Source: Nil

Conflict of Interest: Nil

Cite this article: Muhammad AK, Ali A, Lodhi

$R N$, Kalsoom U. Exploring the Antecedents and Consequences of Mal-Marketing in the Pharmaceutical Industry: A Case Study of Pakistan. RADS J Pharm Pharm Sci. 2020; 8(1):14-25.

*Address of Correspondence Author: aasir.ali@uos.edu.pk

\section{ABSTRACT}

Background: Mal-practices are the unethical marketing practices which are undertaken by mostly pharmaceutical companies to influence the doctors to prescribe their products to the patients.

Objective: This study aimed to identify different kinds of mal-practices that exist in pharmaceutical companies of Pakistan and to inquire how these malpractices influence the financial and health position of the patients.

Methods: The exploration is based on interpretivism research paradigm with intention to underpinning in-depth realities. Data were collected through audio and video recorded semi-structured interviews from the doctors, pharmacists, and medical representatives of different pharmaceutical companies in Pakistan. Qualitative data was analyzed via NVivo software to explore different themes of the study.

Results: Outcomes of this study demonstrate various kinds of mal-practices by pharmaceutical companies. The research that is reported in this research paper is groundbreaking and innovative.

Conclusion: Findings suggest that pharmaceutical mal practices have ultimate impact on patients' health and their pockets. Clients suffer from prolonged treatment, expensive medication, additional unneeded medicine, health hazards and below standard medication.

Keywords: Medical Ethics, Pharmaceutical Marketing, Mal-practices, Patient Health, Well-being.

\section{INTRODUCTION}

Pharmaceutical marketing is not a new concept. It is used for many years by pharmaceutical organizations to boost their sales utilizing many tactics. Pharmaceutical companies are the real followers of Selling Concept in Marketing. [1]

In pharmaceutical marketing medical representatives are used as a direct marketing approach that creates a link between physician and company. [2] The habit of medicine recommending of the doctor is reliant upon the medical information, relationship with the pharmaceutical industry and persistent connection with them. The prescribing habit of the doctors may change with the help of gifts, international or national CME (Continuous Medical Education), marketing tools like detailing aid, product samples, information 
of the product, and expertise of the medical representatives. [3]

Physicians and drug manufacturing companies are equally responsible for mal-practices. However, in some cases, pharmaceutical companies are more responsible for starting mal-practices. But after its beginning, physicians are the main participant for these mal-practices. Because, they are asked to fulfill the personal, financial and professional needs. [4]

The moral requirements highlighted by the World Health Organization (WHO) are that pharmaceutical marketing practices must be ethical, correct, solid, honest and clear. In various countries, organizations do not follow this universal model. Numerous investigations have shown that marketing employees of drug manufacturing companies provide inferior quality, inadequate, unconfirmed, dubious and deceiving claims that comes under pharmaceutical mal-practices. [5]

In Pakistan, mal-practices of pharmaceutical marketing are a serious issue and are increasing day by day because the pharmaceutical industry is growing rapidly. Now, this issue has become real-time violence and our community is suffering from this. Consequently, the issue needs to be addressed. A few studies have tried to address the dilemma from other perspectives in various regions of the world, but this area is neglected, especially in Sub-Continent i.e. India and Pakistan. [4,6]

Just a few studies found, that address only malpractices but there is no study that addresses how these mal-practices effects on patient's health and patients' pocket. Also, Skandrani and Sghaier [7] revealed that; it will be interesting to study comprehensively the stress of competition on the ethnicity of the pharmaceutical organization and the behavior of their medical representative.

Drug promotion and marketing in South Asia, particularly in Pakistan and India, is not an easy job because companies not marketing their products direct to consumers. In this scenario, the doctor's community is playing the middleman role. Patients directly report to doctors and doctors prescribe medicine. That's why pharmaceutical companies target doctor's community to market their products. [8] But pharmaceutical marketing and promotions can negatively impact on patients' health and image of physicians. Similarly, relationship building between physician and pharmaceutical companies is very dangerous for patients. In the resultant of relationship, it will effect on the cost of medicine, quality of medicine and safety in health care. [2]

Medicine manufacturing companies and their representative offers different favors to physicians. Interestingly, most of the time, inexpensive things are provided to remember the name of the organization, such as ballpoints, notebooks and coffee cups with the trade names of products are often circulated in clinics, treatment centers and doctors' offices. [9]

According to a survey, half of the prescribers disclosed that we will prescribe a prominent medicine after attended an event funded or sponsored by the pharmaceutical company. [8] In various detours, the pharmaceutical industry also offers cash and noncash incentives to physicians. For example, experimental trials, financially arrangement for national and international symposia's and conferences, and arranging the medical camps and providing free dosage to patients and refreshments for doctors. [10]

Salespeople are the focused resource for most pharmaceutical companies, this marketing technique and application means that the medical representative makes a relationship, build rapport and create a link with prescribers with the support of various gifts and materials. The tools used for this practice are brochures of medicine information, literature, samples, gifts, promotional gifts at conferences and workshops in the conference and several other tools. [11]

Pharmaceutical companies directly or indirectly have an influence on targeted physician and medicine prescriber. Pharmaceutical companies push products through direct marketing i.e. one to one marketing. [12] Now direct marketing is at a peak in pharmaceutical marketing. Pharmaceutical representative making a relationship with physician or prescriber through different strategies like gifts, pens, notebooks, dinners, lunches, and educational presentation or detailing products. The relationship between pharmaceutical representative and medicine prescriber having an influence on prescribing habit of the medicine prescriber. [13]

\section{MATERIALS AND METHODS}

\section{Research Design}

According to Creswell, [14] qualitative research is the process to know the reality, to find the solution and to 
gain insight into. Qualitative research is usually comprised of conceptual thoughts and convictions to explore a particular phenomenon. $[15,16]$

Case study method has employed in this research because the case study method is different in many ways from policy reports and books i.e. it is short, descriptive and popular. Case study method is used for deep, broad and intense analysis. Case study methodology is very suitable when the researcher has flawless cases that need to find and provide a deep understanding of the phenomena. [17,18]

In this study, pharmaceutical companies and patients were approached as a unit of analysis to find out different and common malpractices, and to explore different consequences on patient health and pocket related. [19]

\section{Sample and Data Collection}

Data were collected through interviews for the current study. Semi-structured and open-ended questions were used as a tool and protocol for data collection. The nature of questions was asked based on how, which, what, whom. In qualitative research, the researcher mostly used open-ended question for getting important data. The qualitative researcher used its own instrument and protocol for data collection rather than others questionnaire and instrument. For data collection, the current study has used purposive sampling technique that is very suitable for qualitative research and especially for case study research as per Creswell. [20]

Data were collected from physicians, patients, medical representatives of the pharmaceutical industry and pharmacist from 5 major cities of Pakistan including Lahore, Islamabad, Faisalabad, Karachi, and Gujranwala. Likewise, two authors travelled to different cities in order to collect data. Before moving, authors made appointments from respondents and brief them about video and audio recorded interview. This process was comprised on two months. Sample size and number of interviewees of each city were: 8 respondents were approached for audio and video recorded interviews from Lahore. Similarly, 5 respondents were asked for interviews from Karachi. Also, 3 respondents were interviewed from Faisalabad. 2 from Gujranwala and 1 from Islamabad. Whereas, 1 group discussion from each city, Lahore, Islamabad, Karachi and Faisalabad.

Table 1. Population Demographics.

\begin{tabular}{|c|c|c|c|c|c|}
\hline Sr. \# & Gender & Age & Profession & Experience & Location \\
\hline 1 & MALE & $40-50$ & General Practitioner & 20 years & Lahore \\
\hline 2 & MALE & $30-40$ & General Practitioner & 10 years & Faisalabad \\
\hline 3 & MALE & $30-40$ & Pharmaceutical Representative & 8 years & Lahore \\
\hline 4 & FEMALE & $20-30$ & Gynecologist & 3 years & Karachi \\
\hline 5 & MALE & $30-40$ & Pharmaceutical Representative & 7 years & Islamabad \\
\hline 6 & FEMALE & $20-30$ & Pharmacist & 4 years & Lahore \\
\hline 7 & MALE & $40-50$ & Medical Officer & 18 years & Faisalabad \\
\hline 8 & MALE & $30-40$ & Pharmaceutical Representative & 5 years & Karachi \\
\hline 9 & MALE & $30-40$ & Pharmacist & 8 years & Gujranwala \\
\hline 10 & MALE & $30-40$ & Pharmacist & 10 years & Lahore \\
\hline 11 & MALE & $40-50$ & Physician & 13 years & Lahore \\
\hline 12 & FEMALE & $30-40$ & Pharmacist & 3 years & Faisalabad \\
\hline 13 & MALE & $30-40$ & Pharmaceutical Representative & 5 years & Gujranwala \\
\hline 14 & MALE & $20-30$ & Pharmaceutical Representative & 4 years & Karachi \\
\hline 15 & MALE & $20-30$ & Pharmaceutical Representative & 5 years & Lahore \\
\hline 16 & FEMALE & $20-30$ & Dermatologist & 6 years & Lahore \\
\hline 17 & MALE & $20-30$ & General Practitioner & 5 years & Karachi \\
\hline 18 & MALE & $20-30$ & Pharmaceutical Representative & 2 years & Faisalabad \\
\hline 19 & MALE & $30-40$ & Gastroenterologist & 7 years & Lahore \\
\hline 20 & MALE & $20-30$ & Pharmaceutical Representative & 3 years & Karachi \\
\hline 21 & Both & $20-50$ & Patients (Group Discussion) & $\mathrm{N} / \mathrm{A}$ & Lahore \\
\hline 22 & Both & $20-50$ & Patients (Group Discussion) & $\mathrm{N} / \mathrm{A}$ & Islamabad \\
\hline 23 & Both & $20-50$ & Patients (Group Discussion) & $\mathrm{N} / \mathrm{A}$ & Karachi \\
\hline 24 & Both & $20-50$ & Patients (Group Discussion) & $\mathrm{N} / \mathrm{A}$ & Faisalabad \\
\hline
\end{tabular}




\section{Conceptual Model for the Study}

Figure 1 illustrates the conceptual model of this study. This model shows that mal marketing practices, which we explored in detail, that is most potential and having impacts on patient's health and having impacts on patients' finance.

Figure 2 showing the percentage of the targeted sample: $\quad 40 \%$ physicians, $40 \%$ medical representatives and $20 \%$ pharmacists.

Figure 3 illustrating the segregation of targeted population citywide: $40 \%$ Lahore, $25 \%$ Karachi, $15 \%$
Faisalabad, 10\% Gujranwala and 5\% Islamabad. Moreover, 1 patients group discussion from each city except Gujranwala.

Data were collected through 20 audios, videorecorded interviews, and 4 group discussions. The method of data collection was significantly dependent on the researcher's ability. Ability is a skill that able to a researcher to ask clear and relevant open-ended questions. [20]

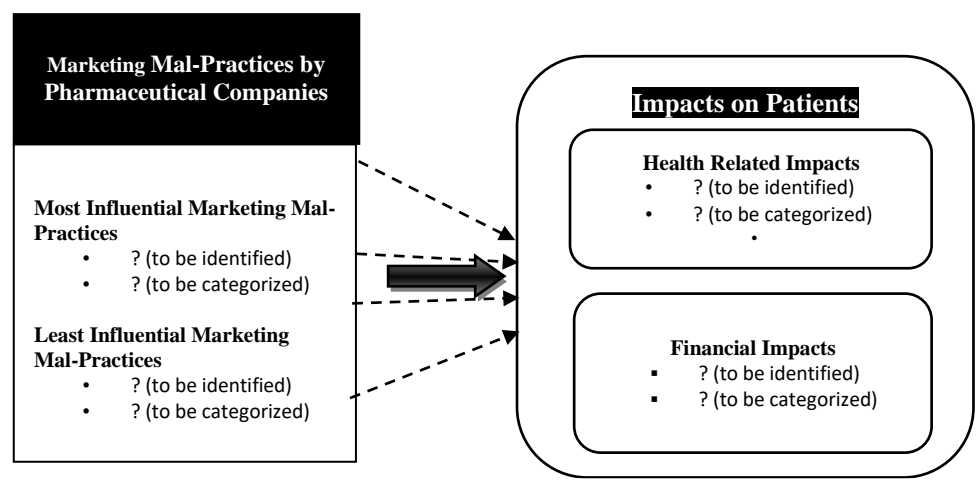

Figure 1. Conceptual Illustration of the Study in respect of Model.

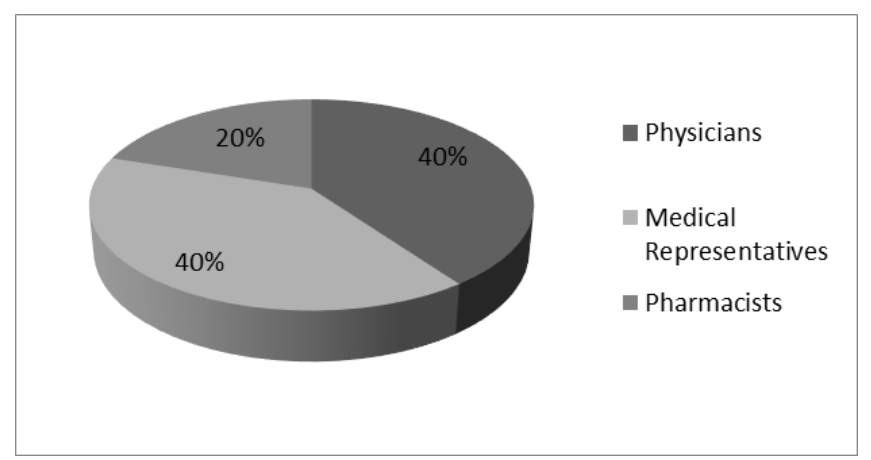

Figure 2. Sample Size Representation.

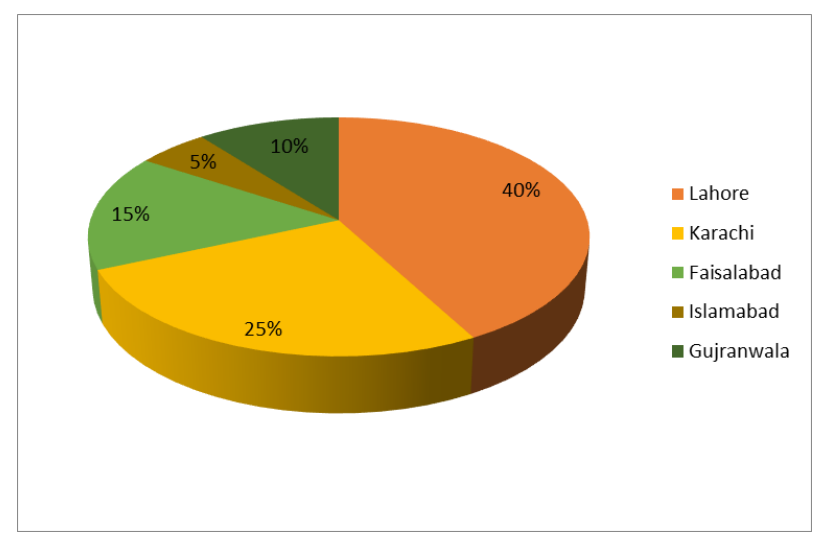

Figure 3. Citywide Disunion of Respondents. 


\section{Data Processing and Analyses}

Data were analyzed through thematic analysis. The thematic analysis contains three steps; first, transcribe the data and convert recorded form into textual form. Secondly, coding the information and third, data processing. [21] NVivo 11 software was utilized in this qualitative research for data processing and data analysis. In the field of qualitative research, the usage of NVivo is growing very rapidly. NVivo can do qualitative data analysis more proficiently and neatly. $[22,23,24,25]$

\section{RESULTS}

The results of the study are in the shape of hierarchy charts. Generally, a hierarchy chart is a graph that displays information as an arrangement of settled rectangles of shifting sizes. For instance, the sizes of the rectangles are showing the data of nodes. More data in nodes mean more size of the nodes. Similarly, less data means smaller sizes of the nodes. All nodes taking space in the graph depending upon the sizes of the nodes.

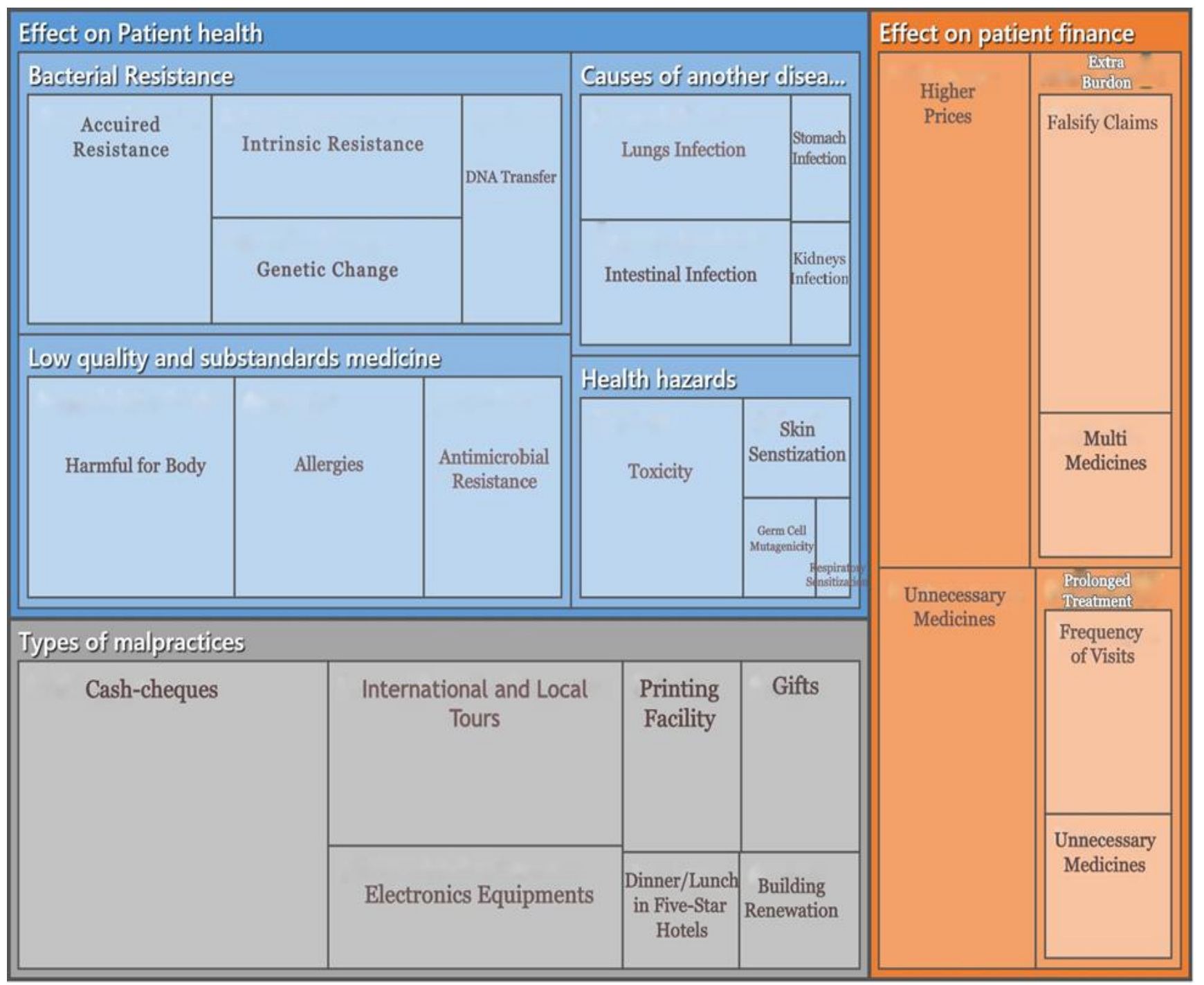

Figure 4. Hierarchy Chart for Findings of the Study

Figure 4 showing the result of the study. This hierarchy chart fulfilling all the objectives of the study and giving us major types of malpractices, effects on patient health and the effects of patient finance. 


\section{Word Tree map}

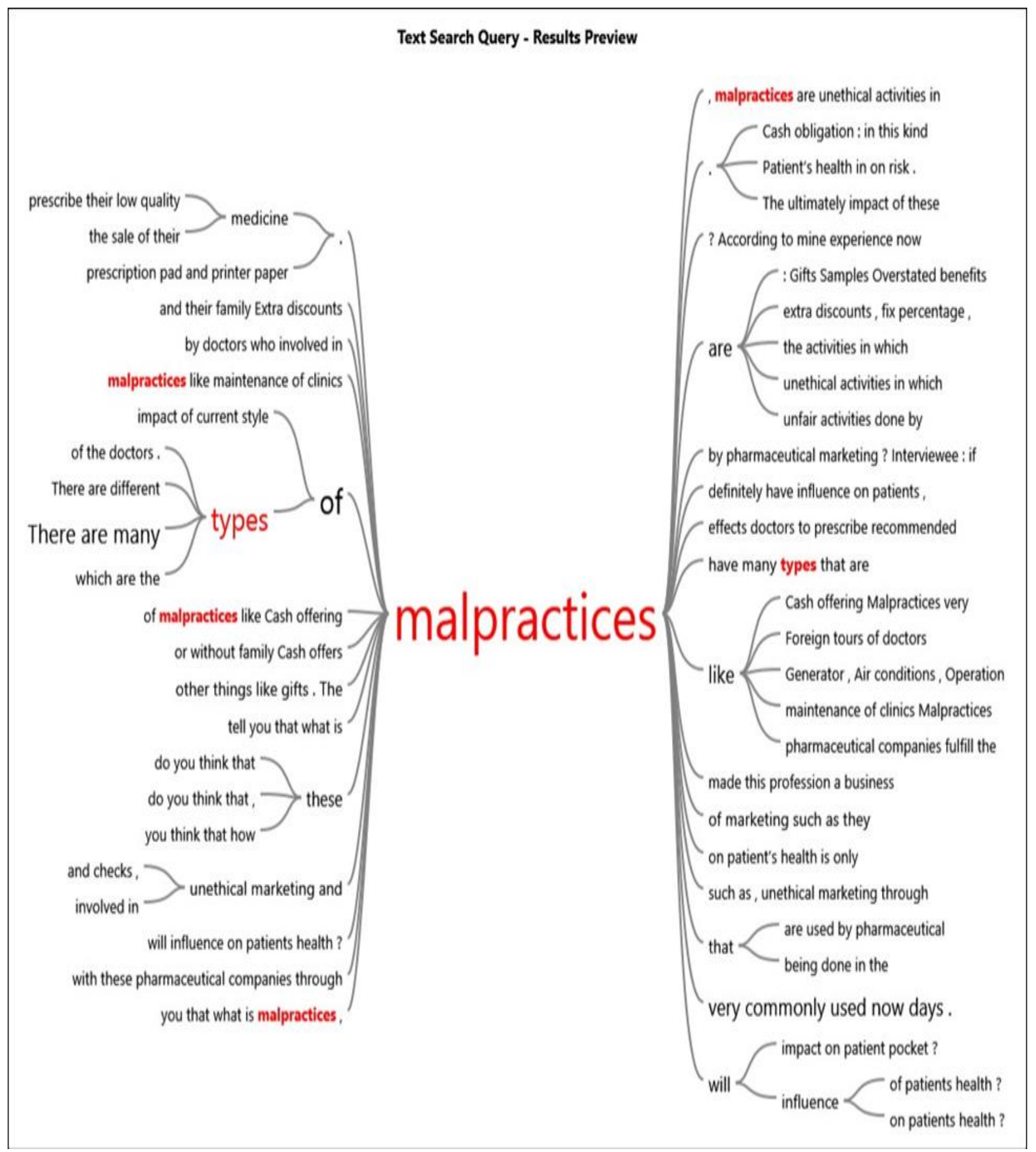

Figure 5. Word Tree Map Showing the Themes of the Study.

Word treemap shows the results and findings in the shape of a tree with twigs, Figure 5 shows the findings of the study through themes of the encircled words with the help of word treemap. 


\section{Word Tag Cloud}

advance assistance base batteries boxes business cars

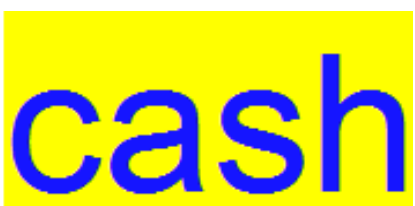

cause cell chemist cheques clinic coffee COSt costly create days decide dinners discounts disease drating effects electronics oquipment equipment's extra tadities family foreign furniture tuture gifts gradation hamrtu hazards health neav hosptals hotels impact incentive inceasing invove involved aptiop laptops tatest atater low maker

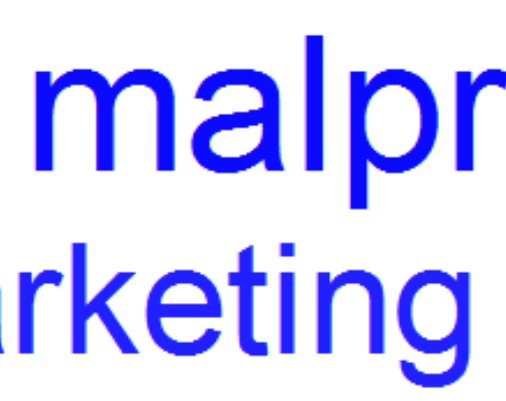
medical mobiles monetary money mugs needs oblige obliging Offers packs paper pens per phones physicians pocket poor prescribe prescription price printer printing private product prolong purpose regardless representative sale samples suffer surgical things tissue tour tours treatment trips unethical ups usage year

Figure 6. Word Tag Cloud Showing Replication of Words.

Figure 6 Word tag cloud is displaying the most repeated words. It illustrates the words which are used again and again and shows the theme. Most frequently used words are in large font and less frequent words are in small font. 


\section{Empirical Model of the Study}

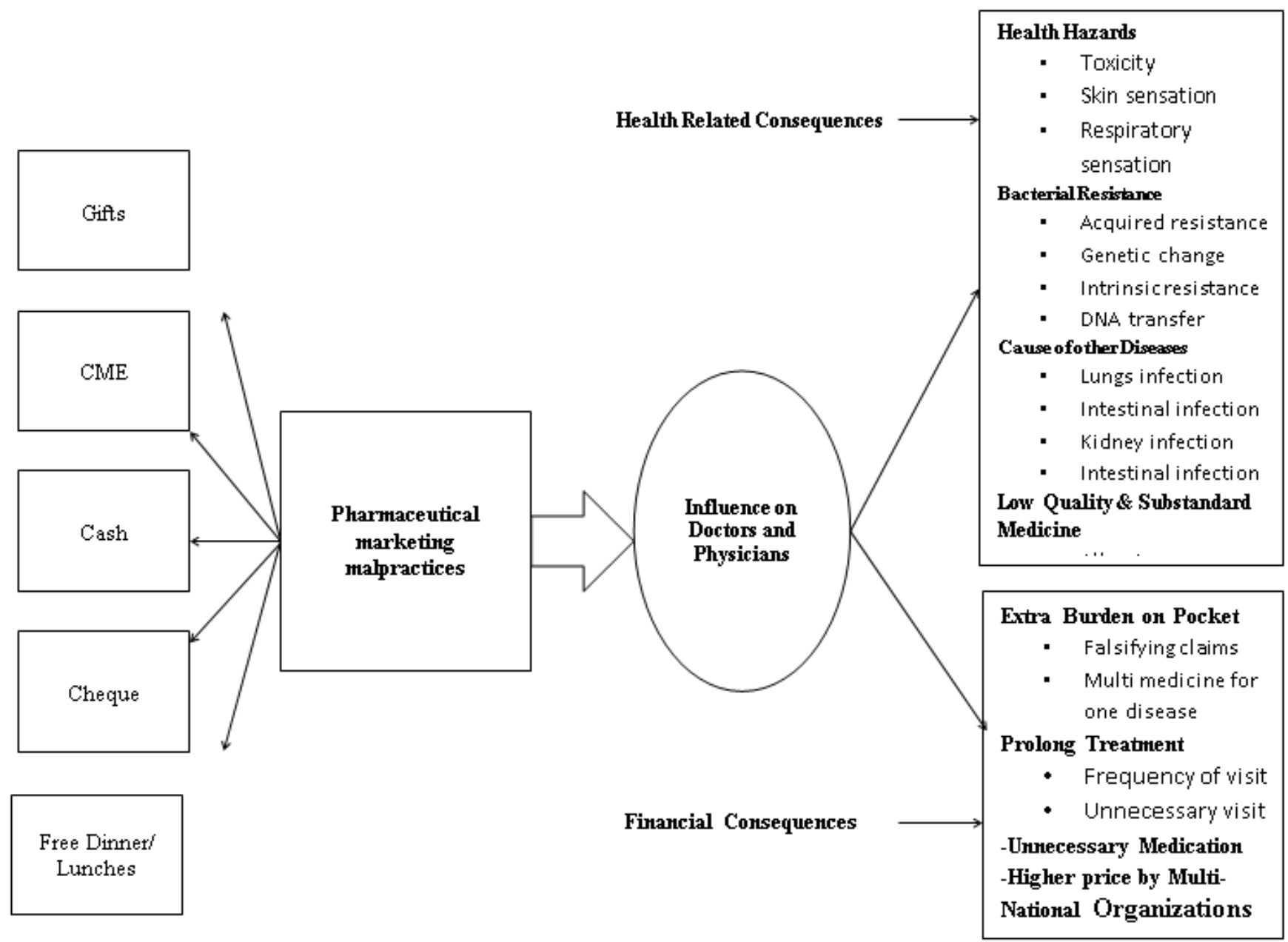

Figure 7. An empirical model of the study.

Figure 7 Empirical model of the study is based on findings. Although, the framework is self-explanatory but in order to avoid any ambiguity, antecedents, and consequences of pharmaceutical marketing malpractices are depicted here. This model gives us a rigorous understanding of this study. Our findingsbased model is showing how pharmaceutical companies use malpractices as a tool to influence doctors. Next, what doctors perform in response to the patients' health and finance.

\section{DISCUSSION}

\section{Types of Malpractices}

The pharmaceutical industry can change the prescribing behavior of the physician through gifts, commission and direct involvement of pharmaceutical employees. [1]

In Pakistan, cash and cheque is a very common type, that local or franchise companies are used to influence doctors and physicians. The findings of the study showed that cash/cheque can change the prescribing habits of the medicine prescriber. After receiving cash/cheque form pharmaceutical company a doctor or physician bound to prescribe their medicine only.

Now a day's profit or money is our wasted interest, and everyone wants to earn more and more. So that's why the mostly doctors and especially new doctors engage with pharmaceutical companies. Companies oblige doctors in many ways, i.e. commission, advance cash and cheque, foreign tours with family, cars etc. (R6) 
According to the findings of the study of international and local tours is much liked by health professionals in Pakistan. After attending pharmaceutical sponsored CME or Tour, health professionals will prescribe their medicine only. Within Pakistan, pharmaceutical companies offering international or local tours to doctors and medical personnel to attend medical conferences to update their knowledge.

Doctor demands a foreign tour with or without a family like New Year tour, international conference, picnic trip with family. (R8)

This study showed electrical/electronics, tools provided by the pharmaceutical industries to doctor's community that have a strong influence on their prescribing. Pharmaceutical companies were fulfilling the needs of the practitioner through electronic equipments. Pharmaceutical companies were offering different types of electronics such as new models of mobile phones, laptops, generators, urgent power suppliers (UPS) and air conditioner.

Pharmaceutical companies dealing with doctors and engaging doctors in many ways like Printing, Cheques and cash, Incentive form, Cell phones offering, Laptop offering, Car offering, Generators, UPS. (R9)

This study suggested that gifts have two types, expensive gifts or less expensive gifts. According to the finding of the study less expensive gifts were used just for making relation with doctors. In another hand, expensive gifts have much influence.

Some doctors prescribe those companies medicines which are fulfilling the unethical needs, like gifts, and foreign tours, lunch, and dinner in five-star hotels with or without family. (R1)

Printing is at the bottom of our hierarchy chart. Its mean printing has very less influence at doctors and physician. Pharmaceutical companies were providing printing facility to doctors just for making a relationship and entering the chamber.

The malpractices that being done in the pharmaceutical marketing are mostly based on the unethical wants. where companies give monetary assistance to doctors and other things like foreign travel, cash, cheques, printing facilities, electronic instruments, surgical instruments, and gifts. (R10)

\section{Patients' Health-Related Effects}

Figure-3 fulfilled the objective number two and gives us the result related to health issues of the patients because of malpractices.
Ahmed [26] narrated that the quality of a drug will suffer if a pharmaceutical company creates an affiliation with the doctors. It will be dangerous for patient health.

After pharmaceutical marketing malpractices, doctors prescribed those company's medicines that fulfilled their financial and other needs. Sometimes, doctors dealt with local or franchise companies those are not registered. Even though, they have not quality medicine or standards of their medicine not up to the mark. that's why patients suffering from health hazards. The finding of the study showed some health hazards of the patients, which are toxicity, skin sensation, germ cell and respiratory sensation.

After accepting a business deal with a pharmaceutical company there are few numbers of doctors for prescribing just because of their unethical extra earning. They can prescribe a poor-quality product which is affecting patient health. (R14)

Some local and franchise companies that don't have its own plant or manufacturing facility and just doing marketing. That's why they cannot confirm the source of raw material, they rely only on manufacturer information. Another reason of low quality and substandard of the medicine is, they involved in malpractices and try to decrease cost and maximizing the profit, that's why they are not focused on quality and standards of the products. Findings of the current study suggested some effects of low quality and substandard medicine on patients' health, these effects are allergies, harmful for the body and antimicrobial resistance.

The low-quality medicines do not provide the real benefit or relief to the patient's disease. (R10)

A cause of another disease is also a major issue with patient health because the findings of the study showed that the causes of another disease create different diseases. If a medicine is not standardized or up to the mark, then it will not able to kill bacteria, virus, and germs properly, that's why it can cause other diseases. The findings of the study explored some major diseases which are very common. That is; infection of the lungs, intestinal infection, kidney infection and stomach infection.

Quality fewer medicines create other disease and health hazards. (R10)

The results of the study showed that resistance against bacteria is also a patient health-related issue. Patients suffered from this just because of 
malpractices. A bacterium creates resistance against antibiotics if antibiotics don't have a quality. Some local manufacturing companies compromised their quality and standard that is why antibiotic did not kill or inhibit bacteria properly. The findings of the present study showed some types of bacterial resistance, acquired resistance, genetic change, intrinsic resistance, and deoxyribonucleic acid (DNA) transfer.

Bacteria create resistance against antibiotics and other consequences can occur. (R4)

\section{Patients' Finance Related Effects}

Figure-3 fulfilled the third objective. The hierarchy chart gave us results regarding patients'

The relationship between physician and pharmaceutical marketing is very dangerous and in the resulting of this relationship, its effects on the cost of medicine, quality of the medicine and safety in health care. [26] The higher cost of medicine is a cause of settlement and dealing between physician and pharmaceutical industry. Pharmaceutical industry offers financial and different types of activities to the physician and prescribers. [27]

The finding of the study suggested us patient will suffer from prolonged treatment just because of the quality and standard of the medicine. Prolonged treatment means the cost of the treatment increased and the patient will bear the extra cost. According to the results of the study frequency of the visit and unnecessary medicine was the reason for prolonged treatment that affects the patients' pocket.

Malpractices affect the patients pocket due to prescribing, quality-less medicine, that increases the treatment duration prolongs from months to years. (R4)

Unnecessary medicine increased the burden on the patient's pocket because some doctors prescribed unnecessary medicine just for increasing the business of pharmaceutical companies and ultimately increased their own commission.

The patient did not get relief due to low-quality medicines. Patients will suffer for a long period of time that's why the cost of treatment will increase. (R10)

\section{CONCLUSION}

The major objectives of the current study were to find out the types of malpractices which are undertaken by Pakistani pharmaceutical industries. We found several types of malpractices. In which, some types are more dangerous and critical for patients' health and patient pocket, like cash, cheque, discounts, commissions, financial obligations, electrical/electronic equipment's and expensive gifts. But on the other hand, printing facilities and inexpensive gifts, lunches, and dinners are less influential.

According to the results of our study, these types have a significant effect on doctors and medicine prescribers. Our study concluded that some doctors and medicine prescribers are like to engage him with such type of activities that offered pharmaceutical companies. The current study contributed to our knowledge that malpractices such as gifts, give and take, electric and electronic appliances, discounts and cash obligation have effects on patients' health and patients' pocket. Health hazards, low quality, and substandard medicine causes of other disease and resistance against bacteria are health-related consequences of the patients. Extra burden, prolonged treatment, high prices, and unnecessary medicine are the finance-related consequences of the patients.

Unfortunately in Pakistan, Pharmaceutical malpractices have been studied generally but neither from marketing point of view nor from the patient's perspective. This study has contributed to our knowledge and shows the types of malpractices in which pharmaceutical companies of Pakistan are indulged. The major contribution of the study is exploring the effects related to health position of the patient and the financial position of the patient. This exploration shows the negative effects of pharmaceutical marketing malpractices on patients.

The findings of the study will play an important role to change pharmaceutical marketing and are expected to play a crucial role to change the thought and perceptions of medicine prescribers. Based on different findings of the exploration, the physician community will come to know about the damages and level of seriousness of the dilemma. They will avoid being an actor in the whole story and will stop contributing in this unethical and immoral activity. That's why this study was very important in the context of Pakistan.

\section{Limitations of the Study and Recommendations}

Regardless of the significant contributions of the study to our knowledge, few limitations are to be addressed. Initially, we took only doctors, medical 
representatives, patients and pharmacists as respondents. But some other actors could also be added, like a pharmacy retailer or chemist and druggist. Moreover, our respondents felt hesitation to give interviews in the video recorded form. A comprehensive and well-funded study can reveal more interesting facts.

In pharmaceutical marketing, the issue is not just the misuse of the techniques of drug advertising and promotion, but the absence and weak enforcement of rules and rules of self-control also responsible for the marketing of medicines could not be controlled. Pharmaceutical companies and doctors should keep in mind that the patient's health is on priority in all cases. Additionally, pharmaceutical companies should follow ethical practices only.

\section{REFERENCES}

1. Ladd E. Pharmaceutical industry sponsorship and the NP prescriber: Policy and practice implications. J Nurse Pract. 2011; 7(2):102-8. https://doi.org/10.1016/j.nurpra.2010.10.005

2. Aamir M, Zaman K. Review of Pakistan pharmaceutical industry: SWOT analysis. International Journal of Business and Information Technology. 2011; 1(1):114-7.

3. Siddiqi A, Hussain S, Parveen G, Malik F, Yasin F, Akram TS, et al. Relevant influence of promotional tools by pharmaceutical industry on prescribing behaviors of doctors: A cross-sectional survey in Pakistan. Afr J Pharm Pharmaco. 2011; 5(13):1623-32.

https://doi.org/10.5897/AJPP11.243

4. Ahmed RR, Saeed A. Pharmaceutical drug promotion practices in Pakistan: Issues in ethical and non-ethical pharmaceutical practices. Middle East J Sci Res. 2014; 20(11):1630-40.

5. Othman N, Vitry Al, Roughead EE, Ismail SB, Omar K. Medicines information provided by pharmaceutical representatives: a comparative study in Australia and Malaysia. BMC public health. 2010; 10(1):743. https://doi.org/10.1186/1471-2458-10-743

6. Grundy Q, Bero L, Malone R. Interactions between non-physician clinicians and industry: a systematic review. PLoS medicine. 2013; 10(11). https://doi.org/10.1371/journal.pmed.1001561

7. Skandrani $H$, Sghaier $M$. The dark side of the pharmaceutical industry. Marketing Intelligence \& Planning. 2016. https://doi.org/10.1108/MIP-062015-0123
8. Singh A, Sharma PK, Malviya R. Eco friendly pharmaceutical packaging material. World Appl Sci J. 2011; 14(11):1703-16.

9. Marco CA, Moskop JC, Solomon RC, Geiderman JM, Larkin GL. Gifts to physicians from the pharmaceutical industry: an ethical analysis. Annals of emergency medicine. 2006; 48(5):51321. https://doi.org/10.1016/j.annemergmed.2005.12.01 3

10. Masood I, Ibrahim M, Hassali M, Ahmed M. Evolution of marketing techniques, adoption in pharmaceutical industry and related issues: a review. J Clin Diagnostic Res. 2009; 3:1942-52.

11. Doran E, Kerridge I, McNeill P, Henry D. Empirical uncertainty and moral contest: A qualitative analysis of the relationship between medical specialists and the pharmaceutical industry in Australia. Social science \& medicine. 2006; 62(6):1510-9. https://doi.org/10.1016/j.socscimed.2005.07.037

12. Hafemeister TL, Bryan SP. Beware those bearing gifts: Physicians' fiduciary duty to avoid pharmaceutical marketing. U Kan L Rev. 2008; 57:491.

13. Gedenk K, Neslin SA, Ailawadi KL. Sales Promotion in: Retailing in the 21st Century: Current and Future Trends. https://doi.org/10.1007/978-3-540-72003-4_24

14. Creswell JW, Creswell JD. Research design: Qualitative, quantitative, and mixed methods approaches. Sage publications; 2017.

15. Denzin NK, Lincoln YS, editors. The Sage handbook of qualitative research. sage; 2011.

16. Yüksel $P$, Yıldırım $S$. Theoretical frameworks, methods, and procedures for conducting phenomenological studies in educational settings. Turk Online J Qual Inq. 2015; 6(1):1-20. https://doi.org/10.17569/tojqi.59813

17. Myers MD. Qualitative Research in Business \& Management Sage Publications. London, UK. 2009.

18. Yin RK. Case study research: Design and methods (applied social research methods). Thousand Oaks, CA: Sage publications; 2014.

19. Lewis $S$. Qualitative inquiry and research design: Choosing among five approaches. Health promotion practice. 2015; 16(4):473-5. https://doi.org/10.1177/1524839915580941

20. Ponelis SR. Using interpretive qualitative case studies for exploratory research in doctoral studies: A case of Information Systems research in 
small and medium enterprises. Int $\mathrm{J}$ Acad Res. 2015; 10(1):535-50. https://doi.org/10.28945/2339

21. Davidson J, Gregorio SD. Qualitative research, technology, and global change. In Qualitative inquiry and global crises 2016. Routledge. https://doi.org/10.4324/9781315421612-4

22. Woods M, Paulus T, Atkins DP, Macklin R. Advancing qualitative research using qualitative data analysis software (QDAS)? Reviewing potential versus practice in published studies using ATLAS. ti and NVivo, 1994-2013. Social Science Computer Review. 2016; 34(5):597-617. https://doi.org/10.1177/0894439315596311

23. Ali A, Muhammad AK. Understanding the Role of Internship as an Activity Based Learning: A Case Study. Journal of Education and Educational Development. 2018; 5(2):92-106. https://doi.org/10.22555/joeed.v5i2.1864
24. Ali A, Lodhi RN. How Facebook addiction affects the personal life of addict students and their family: A case study of Pakistan. Paradigms. 2017; 11(2):184-9.

25. Ali A. Revitalizing Brand Loyalty through Social Media Communication: A double mediation survey. International Journal of Marketing, Communication and New Media. 2019; 7(12).

26. Ahmed RR. Pharmaceutical marketing mix strategy and physician's prescription behavior. The Pharma Innovation. 2014.

27. Al-Areefi MA, Hassali MA, Ibrahim MI. A qualitative study exploring medical representatives' views on current drug promotion techniques in Yemen. Journal of Medical Marketing. 2012; 12(3):143-9. https://doi.org/10.1177/1745790412445295

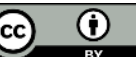

This is an Open Access article distributed under the terms of the Creative Commons Attribution License (http://creativecommons.org/licenses/by/4.0), which permits unrestricted use, distribution, and reproduction in any medium, provided the original work is properly cited. 